\title{
Clay squirt: Local flow dispersion in shale-bearing sandstones
}

\section{Sørensen, Morten Kanne; Fabricius, Ida Lykke}

\section{Published in:}

Geophysics

Link to article, DOI:

10.1190/geo2015-0036.1

Publication date:

2017

Document Version

Publisher's PDF, also known as Version of record

Link back to DTU Orbit

\section{Citation (APA):}

Sørensen, M. K., \& Fabricius, I. L. (2017). Clay squirt: Local flow dispersion in shale-bearing sandstones. Geophysics, 82(1), MR51-MR63. https://doi.org/10.1190/geo2015-0036.1

\section{General rights}

Copyright and moral rights for the publications made accessible in the public portal are retained by the authors and/or other copyright owners and it is a condition of accessing publications that users recognise and abide by the legal requirements associated with these rights.

- Users may download and print one copy of any publication from the public portal for the purpose of private study or research.

- You may not further distribute the material or use it for any profit-making activity or commercial gain

- You may freely distribute the URL identifying the publication in the public portal

If you believe that this document breaches copyright please contact us providing details, and we will remove access to the work immediately and investigate your claim 


\title{
Clay squirt: Local flow dispersion in shale-bearing sandstones
}

\author{
Morten Kanne Sørensen ${ }^{1}$ and Ida Lykke Fabricius ${ }^{1}$
}

\begin{abstract}
Dispersion of elastic-wave velocity is common in sandstone and larger in shaly sandstone than in clean sandstone. Dispersion in fluid-saturated shaly sandstone often exceeds the level expected from the stress-dependent elastic moduli of dry sandstone. The large dispersion has been coined clay squirt and is proposed to originate from a pressure gradient between the clay microporosity and the effective porosity. We have formulated a simple model that quantifies the clay-squirt effect on bulk moduli of sandstone with homogeneously distributed shale laminae or dispersed shale. The model predictions were compared with the literature data. For sandstones with dispersed shale, agreement was found, whereas other sandstones have larger fluid-saturated bulk modulus, possibly due to partially load-bearing shales or heterogeneous shale distribution. The data that agree with the clay-squirt model indicated nonuniform pore pressure in the high-frequency regime and uniform pore pressure in the low-frequency regime. Therefore, our model showed that clay-squirt dispersion can attain a sufficient magnitude to explain much of the large dispersion observed in shaly sandstone.
\end{abstract}

\section{INTRODUCTION}

Clean sandstones are rare in the subsurface, and sandstone reservoirs contain shale more as a rule than as an exception. The elastic moduli of shale bearing sandstones exhibit different porosity trends from those of clean sandstone (Tosaya, 1982; Han, 1986; Klimentos, 1991; Best and McCann, 1995), and the frequency dispersion of elastic moduli is larger in shale-bearing sandstones than in clean ones (Han, 1986; Best et al., 1994; King et al., 2000; King and Marsden, 2002). Several authors have ascribed the dispersion in sandstone to "squirt flow": pore-pressure gradients caused by deformation of compliant pores embedded in the stiffer framework of the sandstone (i.e., microcracks, grain boundaries, etc.) (Mayr and Burkhardt, 2006; Gurevich et al., 2010; Paula and Peruvhina, 2012), and according to this concept, the stress dependency of the elastic moduli of dry sandstone should delimit the possible dispersion in the water-saturated state (Mavko and Jizba, 1991; Shapiro, 2003; Gurevich et al., 2010; David and Zimmerman, 2012). In spite of this theory, dispersion in shaly sandstones has been frequently found to exceed the bounds for dispersion based on the measured stress dependency (Marketos and Best, 2010; Paula and Peruvkhina, 2012). This suggests that there in shaly sandstone is a different contribution to dispersion, which is not directly related to the stress.

According to the classic Biot's theory, velocity dispersion arises in a rock with a given pore size and a given pore fluid because below a critical frequency, the elastic wave propagates in-phase in the solid and the fluid, whereas above the critical frequency, the wave propagates out-of-phase in the two components. The predicted dispersion is too low, though, to explain all the observations. Mavko and Jizba (1991) find that a larger dispersion is predicted due to squirt flow, in which the velocity dispersion is caused by local variations in pore stiffness in a rock frame, so that elastic-wave deformation causes a (frequency-dependent) fluid-pressure gradient between pores. This heterogeneity also causes a stress-dependent stiffness of the dry frame. A stress-independent squirt mechanism requires that a part of the pores is constrained by solids that are not part of the supporting frame. Here, an obvious example is pore space among clay minerals in shaly sandstone because shale can be pore filling and isolated from the applied stress, so that it does not participate in the load-bearing frame (Anstey, 1991). Accordingly, Best et al. (1994) find dispersion and attenuation of fluidsaturated sandstone to increase with shale fraction and suggest that the dispersion is caused by pore-pressure gradients induced in the intrashale porosity, a mechanism they coined "clay squirt." Pore-pressure gradients in shale porosity, clay squirt, could therefore explain the extra dispersion in shaly sandstones. Shale can also be integrated in the load-bearing frame, but the relation between stress and elastic moduli is then more complicated than the corresponding relation for cracks and compliant porosity in the frame (Hudson, 1981; Yin, 1992; Shapiro, 2003; Mondol et al., 2007; Peruvkhina et al., 2008).

\footnotetext{
Manuscript received by the Editor 20 January 2015; revised manuscript received 8 August 2016; published online 09 November 2016.

${ }^{1}$ Technical University of Denmark, Department of Civil Engineering, Lyngby, Denmark. E-mail: morten.kanne@gmail.com; ilfa@byg.dtu.dk.

(c) 2017 Society of Exploration Geophysicists. All rights reserved.
} 
Shale inclusions are different in nature from compliant porosity because they are larger in size, and the physical buildup is more complex; for this reason, the effect of shale on the elastic moduli of fluid-saturated sandstone has frequently been suggested, but rarely modeled. Best et al. (2013) apply the model of Leurer (1997) to explain attenuation of shaly sandstone with either pore filling or structural clay arising from clay squirt, but quantitative evaluation of whether or not induced pressure gradients in the intrashale porosity can explain dispersion in the elastic moduli of saturated shaly sandstones is lacking, and hence it is the aim of the present study.

We develop a simple model to evaluate the maximum magnitude of clay squirt on the bulk modulus of saturated sandstone. We restrict the model to two simple textures to avoid defining the geometry of shale inclusions in the sandstone. The two extreme textures considered are shale present as laminae and shale present as pore fill. The two textures constitute the endmembers in the trend between stress and no stress on the shale inclusions. For shale laminae, the stress applied to the sandstone is projected directly to the shale. For pore-filling shale, the framework of the rock shields the shale entirely. We quantify maximum dispersion due to clay squirt by identifying saturated bulk modulus in a low- and a high-frequency limit, for the two textures considered. In the low-frequency limit, all pore-pressure gradients are relaxed, whereas in the high-frequency limit, pressure has no time to diffuse from the intrashale porosity, whereas pore pressure is relaxed in the macropores. This choice allows us to do fluid substitution by using a low-frequency model. We will not include shear moduli in the model. The $\mathrm{S}$-waves are polarized and therefore require explicit assumption of shale distribution in the sandstone framework.

We formulate the model using Gassmann fluid substitution, in which we determine the induced pressure, respectively, in the intrashale porosity and macroporosity, and then determine pressure diffusion between the two depending on the frequency limit. We model shale-bearing sandstone as composites of two frames: a quartz frame and a shale frame composed of a clay mineral aggregate. We parameterize the frame bulk moduli using the isoframe model expressing frame moduli in terms of isoframe value, porosity, and mineral moduli, where the isoframe value increases with degree of

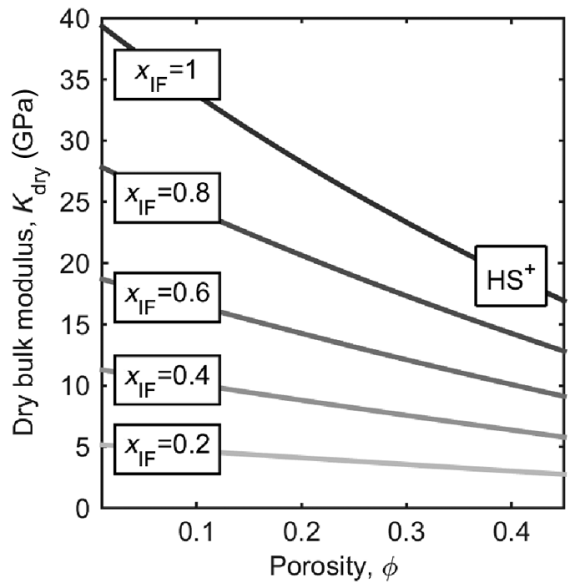

Figure 1. Dry frame bulk modulus as a function of porosity and isoframe value. The upper bound at $x_{\mathrm{IF}}=1$ corresponds to the upper Hashin-Shtrikman bound. Therefore, the coordinates $(\phi$, $x_{\mathrm{IF}}$ ) span the space between the Hashin-Shtrikman bounds. cementation (Fabricius et al., 2010). In the high-frequency limit, the inherent induced pressure predicted by Gassmann's relations for each frame remains independent and the saturated moduli of the frames can be determined by Gassmann relations. In the lowfrequency limit, the pressures in the frames diffuse until an equal pressure is found in the shale and the quartz frame. We determine the average pressure by determining the ratio of pore space between the shale and the quartz frame after compression. The bulk modulus in the low-frequency limit is determined from the average pressure. Input variables are estimated from laboratory data found in the literature.

First, we present the parameterization of the frame moduli using the isoframe model. We then present and justify the choice of input variables needed. The formulation of the Gassmann fluid substitution is then presented. Finally, the model implementations for shale laminae and dispersed shale are presented. To evaluate the model, we compare the predictions with a data set of ultrasonic elastic moduli collected from the literature. Only data for dispersed shale are found, but a qualitative discussion based on observations are conducted to evaluate the case of shale laminae.

\section{METHODS}

\section{Isoframe model}

We parameterize the bulk and shear moduli of a porous frame ( $K_{\text {frame }}, G_{\text {frame }}$ ) with the porosity $\phi$ and the isoframe value $x_{\mathrm{IF}}$. Any frame moduli within the Hashin-Shtrikman bounds defined by the mineral moduli $\left(K_{0}, G_{0}\right)$ can be expressed by the coordinates $\left(\phi, x_{\mathrm{IF}}\right)$. The isoframe value is equivalent to the fraction of the solid cross section $1-\phi$, which participates in the load-bearing frame. The solid cross section fraction not participating in the load-bearing frame $1-x_{\mathrm{IF}}$ is modeled as suspended in the pore fluid. If the entire solid cross section contributes to the load-bearing frame, the isoframe value is one. If the solid material is completely suspended, the isoframe value is zero. An isoframe value of one is only achieved in highly cemented lithologies. The expression for the isoframe model is given in Appendix A. Figure 1 shows the relation among dry frame bulk modulus $K_{\mathrm{dry}}$, isoframe value $x_{\mathrm{IF}}$, and the porosity for clean quartz sandstone.

\section{Gassmann and induced pore pressure}

Undrained compression of a porous framework implies that the fluid mass $m_{f}$ is conserved $\left(d m_{f}=0\right)$. Because the fluid mass is conserved and the frame is compressed, pore pressure $P$ is induced. The rate of induced pore pressure to the applied stress $d P / d \sigma$ is determined by how readily the solid frame is deformed $K_{\text {frame }}$, the fluid modulus $K_{f}$, and the mineral bulk modulus $K_{0}$. The bulk modulus of a saturated frame $K_{\text {sat }}$ is higher than the framework bulk modulus $K_{\text {frame }}$ because of the induced pressure. The rate of induced pore pressure to external stress can be expressed as (Dvorkin et al., 1995)

$$
\frac{d P}{d \sigma}=\frac{1}{\alpha\left(1+\frac{K_{\text {frame }} \phi}{\alpha^{2} F}\right)}, \quad \frac{1}{F}=\frac{1}{K_{f}}+\frac{1}{\phi Q}, \quad Q=\frac{K_{0}}{\alpha-\phi},
$$

where $\alpha=1-K_{\text {frame }} / K_{0}$ is the Biot's coefficient and $K_{f}$ is the bulk modulus of the saturating fluid. Equation 1 is equivalent to Skempton's (1954) $B$ coefficient. Several formulations of Skempton's $B$ 
coefficient have been introduced in the literature (Biot, 1962; Rice and Cleary, 1976; Zimmerman, 2000), and simplification of equation 1 can be achieved by introducing aggregate moduli such as, for example, the pore stiffness, $K_{\phi}=K_{\text {frame }}$ $\phi / \alpha$ (Mavko and Mukerji, 1995).

Figure 2a shows the rate of induced pore pressure for a quartz frame, and Figure $2 b$ shows the rate of induced pore pressure for a shale frame using the parameterization introduced in Figure 1. The rate of induced pore pressure increases with a decreasing frame modulus. From the frame bulk modulus and the rate of induced pore pressure, the saturated bulk modulus can be determined:

$$
K_{\mathrm{sat}}=\frac{K_{\mathrm{frame}}}{1-\alpha \frac{d P}{d \sigma}} .
$$

If the rate of induced pore pressure for a frame is given in equation 1 , equation 2 gives the undrained bulk modulus $K_{\text {sat }}$. An external sink or source of pressure can alter the rate of induced pore pressure from equation 1 and the predicted bulk modulus by equation 2 will be different. The effect of a pressure change on the bulk modulus is quantified in equation 2. Figure 3 shows the effect of induced pore-pressure ratio $d P / d \sigma$ on the bulk modulus for a clean quartz frame and kaolinite frame. It is important to note that Figure 3 illustrates the situation in which $d P / d \sigma$ is changed by an external interaction.

\section{Choice of mineral and frame parameters}

The parameterization of the frame bulk modulus requires input of porosity, isoframe value, and mineral moduli. The isoframe model requires input of the mineral bulk modulus and mineral shear modulus. Mineral moduli for quartz are well-documented, and the choice of moduli is given in Table 1. The isoframe value is related to cementation, so that a higher degree of cementation leads to a high isoframe value. We affix a range of isoframe values to sandstone by calculating the isoframe value from a collection of dry elastic moduli for clean consolidated and unconsolidated sandstones. The data are compiled from the literature (King, 1966; Han, 1986; Jizba, 1991; Best et al., 1994). Figure 4 shows the dry bulk modulus for clean consolidated sandstones and unconsolidated sands versus porosity. The clean condition is defined as samples with a volumetric shale fraction $\chi$ less than $5 \%$ of the total volume. The data are all from ultrasonic measurements on dry rocks recorded at isotropic stress between 40 and $60 \mathrm{MPa}$, so we assume the dry bulk modulus to have negligible dispersion
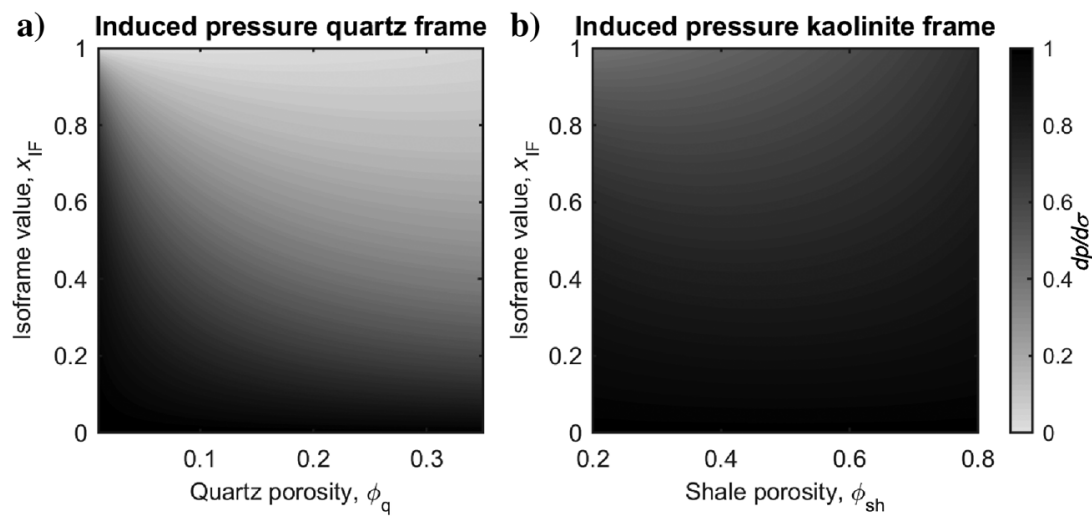

Figure 2. Isoframe value plotted versus rate of induced pore pressure to stress in (a) a quartz frame and (b) a kaolinite frame. The kaolinite frame (b) shows a higher rate of induced pore pressure to stress than the quartz frame (a). a)

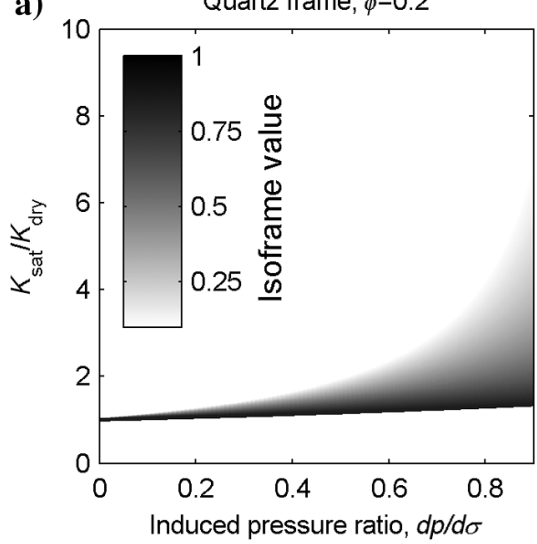

b)

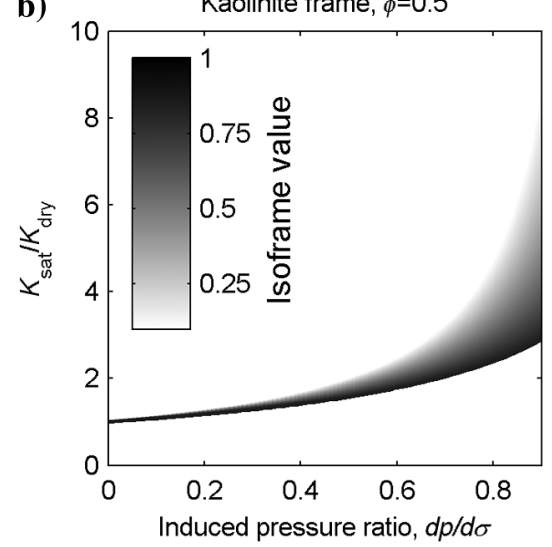

Figure 3. Effect of an induced pore pressure on the saturated bulk modulus for (a) a quartz frame and (b) a kaolinite frame. The kaolinite frame has a higher sensitivity to pore pressure changes.

Table 1. Mineral moduli of clay minerals and quartz published in the literature.

\begin{tabular}{lcccr} 
Mineral & $K_{0}(\mathrm{GPa})$ & $G_{0}(\mathrm{GPa})$ & Method & \multicolumn{1}{c}{ Source } \\
\hline Quartz & 36.6 & 45 & Crystal vibration & Koga et al. (1958) \\
Kaolinite & 11 & 6 & Ultrasonic extrapolation & Vanorio et al. (2003) \\
Kaolinite (dry) & 7.9 & 10.2 & Ultrasonic extrapolation & Mondol et al. (2008) \\
Kaolinite (sat) & 17.8 & 4.7 & Ultrasonic extrapolation & Mondol et al. (2008) \\
Kaolinite & 47.9 & 19.7 & Epoxy cast & Wang et al. (2001) \\
Smectite & 5.75 & 4.02 & Ultrasonic extrapolation & Vanorio et al. (2003) \\
Smectite & 9.3 & 6.9 & Epoxy cast & Wang et al. (2001) \\
Smectite (dry) & 12.3 & 15.6 & Ultrasonic extrapolation & Mondol et al. (2008) \\
Smectite (sat) & 29 & 7.9 & Ultrasonic extrapolation & Mondol et al. (2008) \\
Illite & 60.1 & 25.3 & Epoxy cast & Wang et al. (2001) \\
Chlorite & 164.3 & 51.4 & Epoxy cast & Wang et al. (2001) \\
\hline
\end{tabular}


and be close to the frame bulk modulus. Consolidated sandstones have isoframe values ranging from 0.7 to 1 , whereas unconsolidated sands have isoframe values between 0.2 and 0.35 . Figure 4 also shows that the porosity of clean consolidated sandstone ranges from 0.05 to 0.25 and the porosity of clean unconsolidated sands at high stress ranges from 0.2 to 0.35 .

Clays comprise several mineral groups; the properties of a selection of these are listed in Table 1. It is evident that clay mineral moduli have large uncertainty. We therefore apply a range of values for each mineral modulus. The proper range of frame moduli for a shale frame at a given porosity is also difficult to assess. For shale laminae, the frame properties can be evaluated by observing the relation between ultrasonic velocity and stress for aggregates of clay powders. Figure 5 shows the dry bulk modulus of a kaolinite powder as a function of stress (Yin, 1992). With increasing stress, the porosity decreases and the isoframe value increases, ranging from 0.08 at low differential stress to 0.65 at high differential stress. As clay minerals do not readily form cement, compaction experiments provide a good measure of the modulus development with burial. We therefore use the compaction trend from Figure 5 as guidance for the choice of isoframe values in the case of shale laminae. Burial of 2-5 km corresponds approximately to effective stress of 20 $50 \mathrm{MPa}$ assuming hydrostatic pore pressure. From Figure 5, we find that this stress interval is equivalent to isoframe values between 0.38 and 0.65 , which is, hence, used for shale laminae. The elastic properties of dispersed shale are more complicated to estimate because authigenic clay forms as individual particles in pores and not as connected frames (Wilson and Pittman, 1977).

Dispersed shale is not subjected to an effective stress, and therefore no compaction occurs. Although dispersed shale does not undergo compaction, it still has a nonzero, but small, frame modulus, because the particles are in contact. The frame modulus is related to how the clay is formed in the pores, but no data exist to directly determine the relation. Based on the assumption that compaction is the dominant factor in consolidation of shales, the iso-

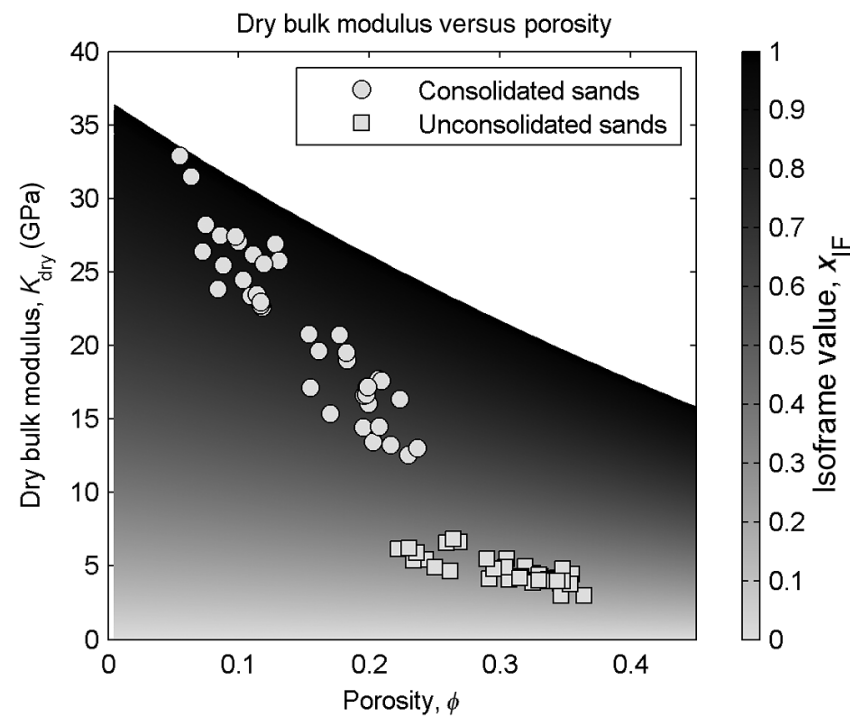

Figure 4. Bulk modulus for dry clean sandstones compared with the isoframe value to estimate relevant $\left(\phi, x_{\mathrm{IF}}\right)$ combinations for a clean quartz frame. Consolidated sandstones have isoframe values in the range of $0.7-1$, and unconsolidated sands have isoframe values in the range of $0.2-0.35$. frame value of dispersed clay assemblages is assumed to be low. We adopt an isoframe value span for dispersed shales of 0.05-0.4.

In addition, the porosity of shale is related to compaction (Mondol et al., 2007). Figure 5 shows the porosity of kaolinite aggregates to vary from 0.6 at low stress to 0.2 at high stress. Hurst and Nadeau (1995) find a wide range of shale porosity in sandstones, depending on whether the shales are load bearing and compacted. We affix a porosity range of $0.2-0.4$ for load-bearing shale, corresponding to a stress interval between 20 and $50 \mathrm{MPa}$ (Figure 5). These porosity values are high when compared with the data published for compacted shale formations (Minshull and White, 1989; Hansen, 1996). Comparison of natural shale compaction trends with compaction curves for synthetic mudstones shows that synthetic mudstones retain a higher porosity at a given stress, possibly due to the higher clay content and consequent better sorting. The mineralogical composition of shale laminae in sandstones may be significantly different from shale formations, solely due to the mechanism of deposition. Based on the data of Hurst and Nadeau (1995), we assign a porosity range from 0.4 to 0.8 for dispersed shale.

\section{FREQUENCY RANGE}

The model we develop quantifies bulk modulus dispersion in the undrained frequency range relevant for elastic moduli based on typical borehole logging and laboratory data (Pimienta et al., 2015). We define the dispersion as the difference between a high frequency bulk modulus and a low frequency bulk modulus. To formulate these two states, the high- and low-frequency limits must be defined. First, all frequencies are low enough for the composite of sand and shale to be in the long-wavelength limit. This means that wavelength $\lambda$ is always longer than the heterogeneities characterizing the mixture of sand and shale. For the laminated texture, this restriction means that $\lambda \gg L$, where $L$ is the thickness of a lamina.

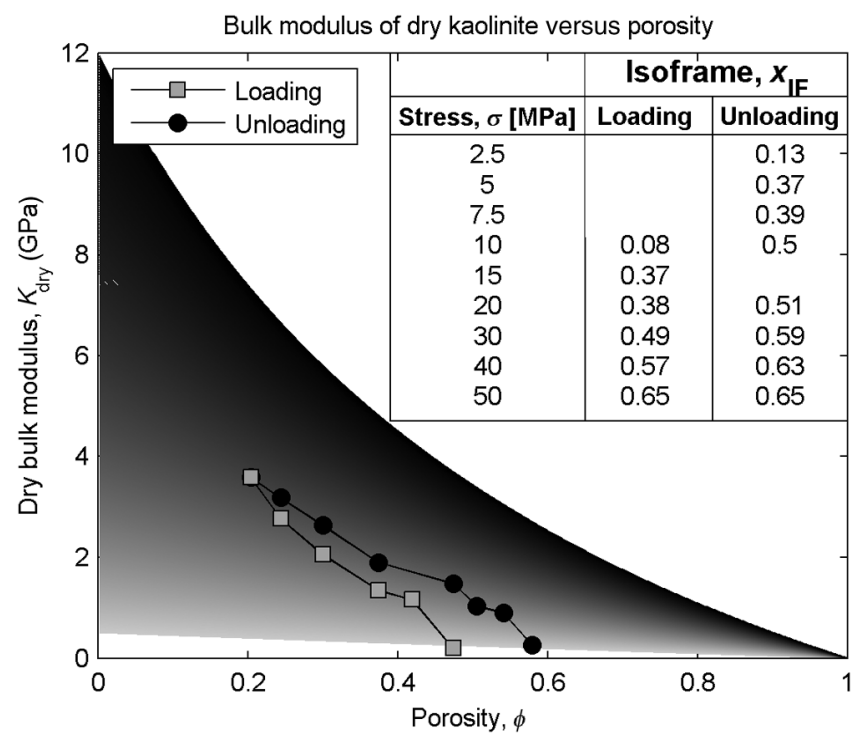

Figure 5. Dry bulk modulus of kaolinite aggregate versus porosity and compared with isoframe value by assuming mineral moduli, $K_{0}^{c}=12 \mathrm{GPa}$ and $K_{0}^{c}=6 \mathrm{GPa}$ (Vanorio et al., 2003). Isoframe values increase and porosity decreases with increasing stress. An appropriate $\left(\phi, x_{\mathrm{IF}}\right)$ combination for kaolinite compacted at 20 $50 \mathrm{MPa}$ is the porosity between 0.2 and 0.4 and isoframe values between 0.38 and 0.65 . 
For the dispersed shale texture, the long-wavelength restriction requires the wavelength to be much longer than the pore size of the sand frame. The high-frequency limit is therefore defined as the frequency at which pore-pressure diffusion from the shale porosity is negligible, but the system is still in the long-wavelength limit. The low-frequency limit is at a frequency at which all pore-pressure gradients have relaxed.

\section{MODEL FORMULATION: SHALE LAMINAE}

The laminated model is illustrated in Figure 6. When the shale is distributed as laminae between layers of clean sand, the shale and sand frames will be subjected to the same externally applied stress $\sigma$. In the high-frequency limit, the quartz and the shale frames are undrained individually, so that

$$
\frac{d m_{q}^{\mathrm{HF}}}{d \sigma}=\frac{d m_{\mathrm{sh}}^{\mathrm{HF}}}{d \sigma}=0
$$

where $d m_{q}^{\mathrm{HF}}$ is the change in fluid mass in the quartz frame at high frequency and $d m_{\mathrm{sh}}^{\mathrm{HF}}$ is the change in fluid mass in the shale frame at high frequency. With the frames being simultaneously undrained, the induced pore pressure can be determined by equation 1 for each frame individually and the saturated bulk modulus of each layer can be achieved by inserting the induced pore pressure into equation 2 . Because the same external stress applies to all layers, the saturated bulk modulus of the quartz frame $K_{q}^{\text {sat }}$ and the shale frame $K_{\mathrm{sh}}^{\mathrm{sat}}$ can be combined to give the high-frequency saturated bulk modulus of the rock $K_{\mathrm{HF}}$ by the Reuss average,

$$
\frac{1}{K_{\mathrm{HF}}}=\frac{1-\chi}{K_{q}^{\mathrm{sat}}}+\frac{\chi}{K_{\mathrm{sh}}^{\mathrm{sat}}}
$$

where $\chi$ denotes the bulk volume fraction of shale including the shale porosity. A higher pore pressure is induced in the shale frame than in the quartz frame due to the difference in the frame bulk moduli as illustrated in Figure 2.

During an undrained low-frequency deformation, the initial induced pore pressures in the layers are determined by equation 1 , but the low frequency allows pore-pressure communication between the two frames, and fluid flows from the shale frame to the quartz frame. This equilibrates the pore pressure to a uniform value in the entire pore space and causes a reduction of the shale pore pressure and an extra compression of the shale frame as well as, at the same time, an increase in the pore pressure of the quartz frame, and consequently, less compression of the quartz frame. Because the pore pressure has equilibrated, the bulk modulus of the laminated rock can then be determined by a Reuss average of the individual frames. The individual frames are no longer undrained, but the composite of the two frames is undrained, whereby the mass of fluid moved from the shale frame must equal the fluid mass added to the quartz frame

$$
\frac{d m_{q}^{\mathrm{HF}}}{d \sigma}-\frac{d m_{q}^{\mathrm{LF}}}{d \sigma}=-\left(\frac{d m_{\mathrm{sh}}^{\mathrm{HF}}}{d \sigma}-\frac{d m_{\mathrm{sh}}^{\mathrm{LF}}}{d \sigma}\right),
$$

where $d m_{q}^{\mathrm{LF}}$ is the change in fluid mass in the quartz frame in the low-frequency regime and $d m_{\mathrm{sh}}^{\mathrm{LF}}$ is the corresponding value for the shale frame. The compressibility $C_{\mathrm{pp}}$ relating pore-volume com- pression to pore-pressure change at constant external stress was formulated by Zimmerman et al. (1986) as

$$
C_{\mathrm{pp}}=\left.\frac{1}{V_{p}} \frac{\partial V_{p}}{\partial P}\right|_{\sigma}=\frac{1}{\phi}\left(\frac{1}{K_{\mathrm{frame}}}-\frac{1+\phi}{K_{0}} \frac{1}{K_{0}}\right),
$$

where $V_{p}$ denotes the pore volume. By using this expression, a change in fluid mass can be written as a function of the induced pore pressure:

$$
\frac{d m}{d \sigma}=\rho\left(\frac{d V_{p}}{d \sigma}+\frac{V_{p}}{K_{f}} \frac{d P}{d \sigma}\right)=V_{p} \rho\left(C_{\mathrm{pp}}+\frac{1}{K_{f}}\right) \frac{d P}{d \sigma},
$$

where the density of the saturating fluid is given by $\rho$. We substitute equation 7 into equation 5 and normalize all terms to the total pore volume, $V_{p}=V_{p}^{q}+V_{p}^{\mathrm{sh}}$, which is the sum of the quartz frame pore volume $V_{p}^{q}$ and the shale frame pore volume $V_{p}^{\mathrm{sh}}$. Normalization to the total pore volume produces the fraction of the total pore volume contained in the quartz frame $f_{q}$ and the fraction of the total pore volume contained in the shale frame $f_{\mathrm{sh}}$ :

$$
\begin{gathered}
f_{q}=\frac{V_{p}^{q}}{V_{p}}=\frac{(1-\chi) \phi_{q}}{\phi}, \\
f_{\mathrm{sh}}=\frac{V_{p}^{\mathrm{sh}}}{V_{p}}=\frac{\chi \phi_{\mathrm{sh}}}{\phi} .
\end{gathered}
$$

We get

$$
\begin{aligned}
\frac{d P^{\mathrm{LF}}}{d \sigma}= & \frac{1}{A}\left(f_{q} \frac{d P_{q}^{\mathrm{HF}}}{d \sigma}\left(C_{\mathrm{pp}}^{q}+1 / K_{f}\right)\right. \\
& \left.+f_{\mathrm{sh}} \frac{d P_{\mathrm{sh}}^{\mathrm{HF}}}{d \sigma}\left(C_{\mathrm{pp}}^{\mathrm{sh}}+1 / K_{f}\right)\right),
\end{aligned}
$$

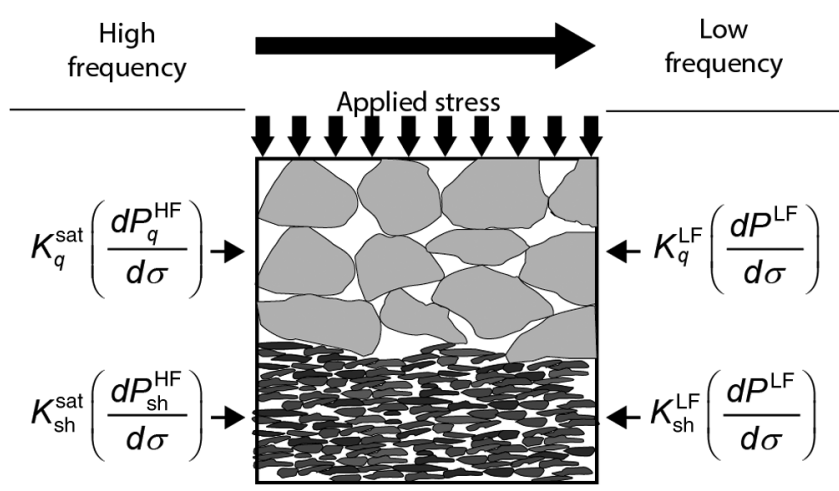

Figure 6. Illustration of the laminated model. At the high-frequency limit, the pore pressures in the quartz and shale frame are different. The pore pressures in the two frames are the pressures induced by compression of the specific frame according to Gassmann (equation 1). For the low-frequency limit, fluid flows from the shale frame to the quartz frame, so that the pressure in the two frames becomes equal. Equilibration of the pressure means that the pore pressure in the shale decreases and the pore pressure in the quartz increases. The change in pore pressure results in a change in the bulk modulus of the sandstone. 
where $A=1 / K_{f}+f_{q} C_{\mathrm{pp}}^{q}+f_{\mathrm{sh}} C_{\mathrm{pp}}^{\mathrm{sh}}, \mathrm{dP}^{\mathrm{LF}}$ is the averaged pore pressure induced in the entire porosity at low frequency, $d P_{q}^{\mathrm{HF}}$ is the pressure induced in the quartz porosity at high frequency, $d P_{\mathrm{sh}}^{\mathrm{HF}}$ is the induced pressure at high frequency for the shale porosity, $C_{\mathrm{pp}}^{q}$ is the pore compressibility with changing pore pressure for the quartz frame, and $C_{\mathrm{pp}}^{\mathrm{sh}}$ is the same entity for the shale frame. Equation 9 relates the average pressure to the pressure induced in the individual frames, the framework bulk moduli, and the pore-volume fractions contained in the individual frames. The induced pore pressure in the low-frequency state from equation 9 can be substituted into equation 2 to determine the bulk moduli of the quartz and shale frames at the relaxed pore pressure $\left(K_{q}^{\mathrm{LF}}, K_{\mathrm{sh}}^{\mathrm{LF}}\right)$. The low-frequency composite bulk modulus can then be determined by a Reuss average:

$$
\frac{1}{K_{\mathrm{LF}}}=\frac{1-\chi}{K_{q}^{\mathrm{LF}}}+\frac{\chi}{K_{\mathrm{sh}}^{\mathrm{LF}}} .
$$

The dispersion on the bulk modulus caused by clay squirt is then given by the difference between the high-frequency composite bulk modulus $K_{\mathrm{HF}}$ and the low-frequency composite bulk modulus $K_{\mathrm{LF}}$.

\section{MODEL FORMULATION: DISPERSED SHALE}

Dispersed shale is distributed entirely in the pores of the quartz frame, and the shale frame is therefore shielded from a stress applied to the rock. In the drained state, the modulus of sandstone with dispersed shale is equal to the modulus of the quartz frame. In the undrained state, the compression of the quartz frame induces a pressure in the pores of the quartz frame. The magnitude of the induced pressure depends on how much of the pore space $\phi_{q}$ is taken up by shale and on the modulus of that shale. We assume that there is microporosity within the shale $\phi_{\mathrm{sh}}$. When a load is applied to the quartz frame, a pore pressure is induced around the shale, but the pressure in the shale porosity can differ from the pressure outside the shale (Figure 7).

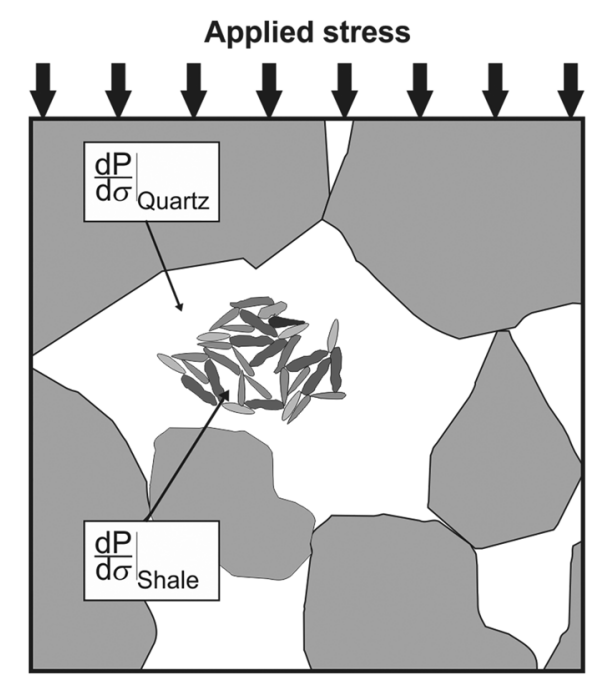

Figure 7. Sketch of the dispersed shale case. The external stress $\sigma$ acts on the quartz frame inducing a pore pressure in the quartz frame at the rate, $d P /\left.d \sigma\right|_{\text {quartz. }}$. The shale frame is only stressed by the induced pore pressure in the quartz frame. The rate of pore pressure increase in the shale frame is, therefore, $d P /\left.d \sigma\right|_{\text {quartz }} d P /\left.d \sigma\right|_{\text {shale }}$.
At the high-frequency limit, the relevant modulus for the shale is the saturated bulk modulus of the shale frame $K_{\mathrm{sh}}^{\mathrm{sat}}$. In this case, the pore fluid in the sandstone is a suspension of a shale part given by $S_{\mathrm{sh}}=\chi / \phi_{\theta}$, and the fluid outside the shale given by $1-S_{\mathrm{sh}}$. The effective modulus of the shale suspension can then be determined as the Reuss average

$$
\frac{1}{K_{\mathrm{sus}}^{\mathrm{HF}}}=\frac{1-S_{\mathrm{sh}}}{K_{f}}+\frac{S_{\mathrm{sh}}}{K_{\mathrm{sh}}^{\mathrm{sat}}} .
$$

If the frequency is low enough, the pressures will equilibrate, so that all the fluid in the pore space, inside and outside the shale is at the same pressure (Figure 7). Then, the effective pore-filling modulus will correspond to a suspension of a solid clay fraction given by $S_{c}=\chi\left(1-\phi_{\mathrm{sh}}\right) / \phi_{q}$, and all of the fluid in the pore space given by $1-S_{c}$. Again, the modulus of this suspension is calculated by a Reuss average:

$$
\frac{1}{K_{\mathrm{sus}}^{\mathrm{LF}}}=\frac{1-S_{c}}{K_{f}}+\frac{S_{c}}{K_{0}^{c}} .
$$

The clay fraction in the pore fluid contributes to the suspension by the clay mineral bulk modulus $K_{0}^{c}$.

With the formulation of the effective fluid modulus at low- and high-frequency limits, we use Gassmann fluid substitution to determine the bulk modulus at low- and high-frequency limits. The sandstone bulk modulus at the high-frequency limit is obtained by fluid substituting the high-frequency limit fluid modulus from equation 11 into the quartz frame bulk modulus. The sandstone bulk modulus at low frequency is obtained by fluid substituting the quartz frame with the low-frequency fluid modulus in equation 12.

To be contained in the pores of the quartz frame, the shale fraction must be lower than the porosity of the quartz frame $\chi<\phi_{q}$ (Marion and Nur, 1991). This shale fraction is the absolute maximum for the dispersed shale model, but the model breaks down at a slightly lower shale fraction because first, the shale must not span the pores. If the shale spans the pores, it may sustain a shear load and the problem becomes that of solid substitution instead of fluid substitution (Ciz and Shapiro, 2007; Makarynska et al., 2010; Saxena and Mavko, 2014). The model also assumes pressure equilibration at low frequency, which at compression requires the transfer of a finite volume of water into the shale porosity from the fluid surrounding the shale. When $\chi=\phi_{q}$, there is no volume of fluid outside the shale, and hence no pressure equilibration can occur. For these reasons, the fundamental assumptions of the model presented for dispersed shale breaks down at a shale fraction close to, but lower than, the porosity of the quartz frame.

\section{RESULTS FOR SHALE LAMINAE}

The model considering shale laminae relies on seven parameters $\chi, \phi_{q}, x_{\mathrm{IF}}^{q}, \phi_{\mathrm{sh}}, x_{\mathrm{IF}}^{\mathrm{sh}}, K_{0}^{c}$, and $G_{0}^{c}$, complicating a full analysis. Figure 8 shows the results of the model in the case of shale laminae in a consolidated quartz frame with a porosity of 0.2. Three sets of different clay moduli are chosen; smectite from ultrasonic extrapolation, kaolinite from ultrasonic extrapolation, and kaolinite from epoxy cast (Table 1). The porosity of the shale frame is set to 0.4 corresponding to compacted shale (Figure 5). The difference between low- and high-frequency bulk moduli is higher when 
the contrast between quartz and clay mineral moduli is high. Because we have fixed the isoframe value to a range of $0.38-0.65$, the mineral and the frame moduli are coupled. Therefore, the dependence on mineral modulus also reflects the relation between clay mineral bulk and shale frame moduli.

The magnitude of the clay-squirt effect as a function of shale frame bulk modulus and shale porosity is shown in Figure 9 for a kaolinite mineralogy $K_{0}^{c}=12 \mathrm{GPa}$, with a constant quartz frame bulk modulus. We find that for low $x_{\mathrm{IF}}^{\mathrm{sh}}$ and consequently low shale frame bulk modulus, the possible effect of clay squirt is high. This is because a higher pore pressure is induced in a soft shale frame (Figure 3).

\section{RESULTS FOR DISPERSED SHALE}

A significantly smaller difference between the low- and high-frequency saturated bulk moduli is modeled for sandstone with dispersed shale as compared with laminated shale (Figures 8 and 10 illustrating the same three clay moduli). The sandstone frame used for Figure 10 has a porosity of 0.3 , whereby the maximum shale fraction is 0.3 . The model illustrates that the clay-squirt effect increases monotonically with shale content, but fails to show that the dispersion will be absent when the entire porosity is filled with shale. At this limit, only one type of porosity exists and the model is not valid. Contrary to in the laminated case, the dispersion increases with increasing clay mineral bulk modulus. This is because the pore-pressure difference between the shale and the open porosities increases with shale frame bulk modulus, and at a fixed isoframe value, the shale frame bulk modulus increases with clay mineral modulus. For a clay mineral bulk modulus of $12 \mathrm{GPa}$, the maximum dispersion is only approximately $1 \mathrm{GPa}$. If the mineral bulk modulus is higher, a higher effect can be expected.

\section{COMPARISON WITH DATA}

We compare the predictions of the model derived in this study with dispersion quantified from published ultrasonic velocity data so that we can evaluate whether the observed dispersion could arise from clay squirt. We also extract the apparent moduli for shale inclusions and compare them with the literature data for synthetic mudstones and shales. We derive the quasi-static saturated bulk modulus by Gassmann fluid substitution of modulus data for dry sandstone, and compare it with the bulk modulus of fluid-saturated sandstone as measured at ultrasonic frequency. The difference between the quasistatic prediction and the ultrasonic modulus of the fluid-saturated sample is assumed to be the dispersion. We found no data for laminated sandstones, so we base the comparison on an assumption of dispersed shale. The data set collected from the literature represents sandstones with varying shale content from a wide range of localities (King, 1966; Han, 1986; Best, 1992; Figure 11). Volumetric shale content was in all studies determined by image analysis of thin sections. All data points involve solid density, porosity, fluid properties, and a set of ultrasonic elastic P- and Swave velocities at dry and at saturated conditions.
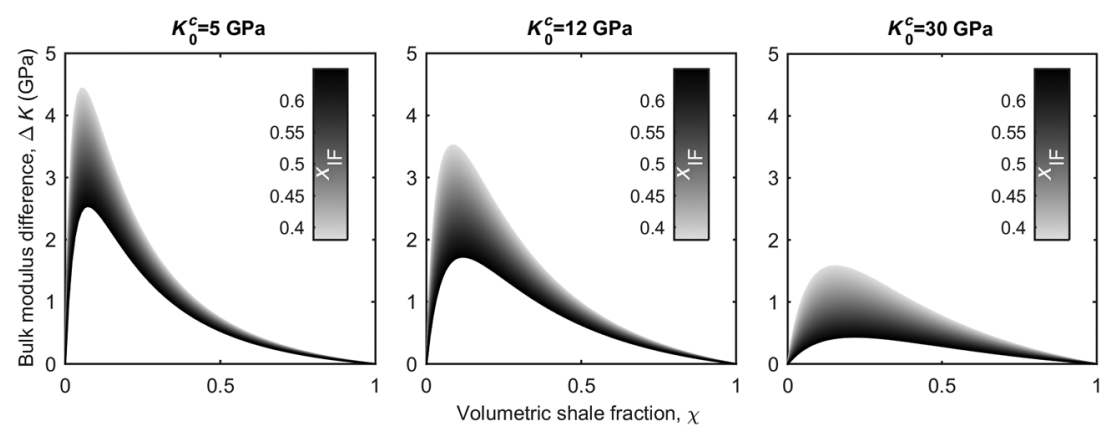

Figure 8. Clay-squirt dispersion of saturated bulk modulus of sandstone with shale laminae assuming different clay mineral moduli. The clay-squirt effect increases with decreasing clay mineral modulus. The effect is drastically higher at shale fractions approximately $\chi \approx 0.2$.
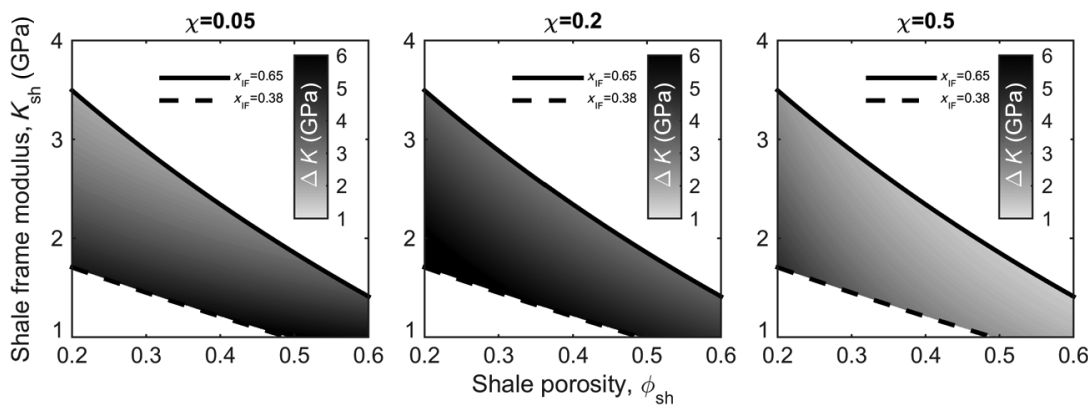

Figure 9. Clay-squirt dispersion of saturated bulk modulus of sandstone with shale laminae as a function of shale porosity and isoframe value. The three plots show different shale fractions. The clay-squirt effect decreases as the frame bulk modulus of the shale increases.
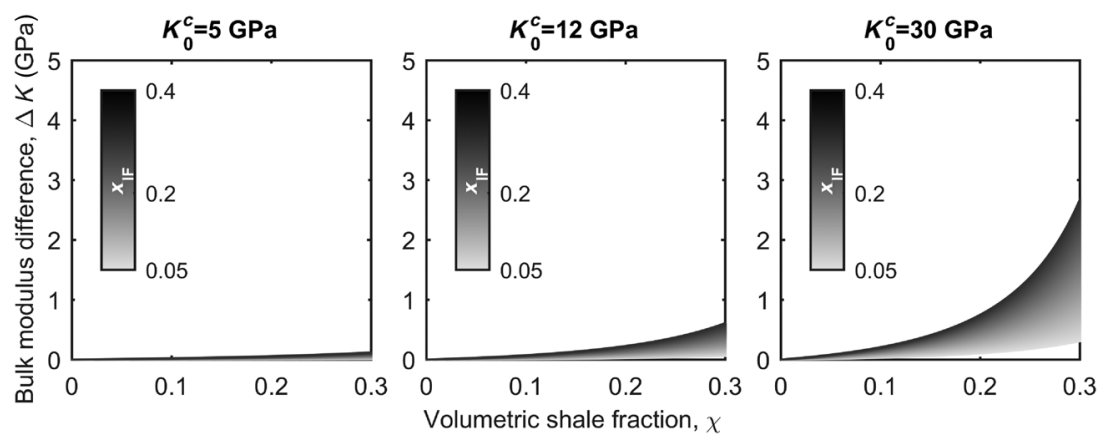

Figure 10. Clay-squirt dispersion of the saturated bulk modulus of sandstone with dispersed clay with three different clay mineral moduli. Clay-squirt dispersion increases as the clay mineral modulus increases due to a higher shielding of the microporosity within the shale frame. 
To quantify the dispersion, we first establish the porosity of the solid frame $\phi_{\text {frame }}$ :

$$
\phi_{\text {frame }}=\phi+\left(1-\phi_{\mathrm{sh}}\right) \chi
$$

The frame porosity corresponds to the quartz frame porosity in the model. The frame porosity can be estimated by comparing the measured bulk modulus in the dry state (negligible $K_{f}$ ) with a correlation between the porosity and bulk moduli. Gal et al. $(1998,1999)$ use a modified upper Hashin-Shtrikman (MUHS) bound to correlate bulk modulus and porosity for clay-free dry sandstone. We use the MUHS bound with a critical porosity of $\phi_{c}=0.45$ and establish the frame porosity for each sample. We then calculate the apparent pore-filling modulus $K_{\mathrm{pfa}}^{\mathrm{gass}}$ from Gassmann fluid substitution:

$$
\begin{aligned}
A & =\frac{K_{\mathrm{pfa}}^{\mathrm{gass}}}{\phi_{\mathrm{frame}}\left(K_{0}-K_{\mathrm{pfa}}^{\text {gass }}\right)}=\frac{K_{\mathrm{sat}}}{K_{0}-K_{\mathrm{sat}}}-\frac{K_{\mathrm{dry}}}{K_{0}-K_{\mathrm{dry}}}, \\
K_{\mathrm{pfa}}^{\mathrm{gass}} & =\frac{A K_{0} \phi_{\text {frame }}}{1+A \phi_{\text {frame }}},
\end{aligned}
$$

and the question is now to which extent $K_{\text {pfa }}^{\text {gass }}$ can be modeled.

To model $K_{\text {pfa }}^{\text {gass }}$, we need the elastic moduli of clay minerals, but they are very uncertain as evident from values tabulated in Table 1 , but we assume a clay mineral bulk modulus higher than the fluid
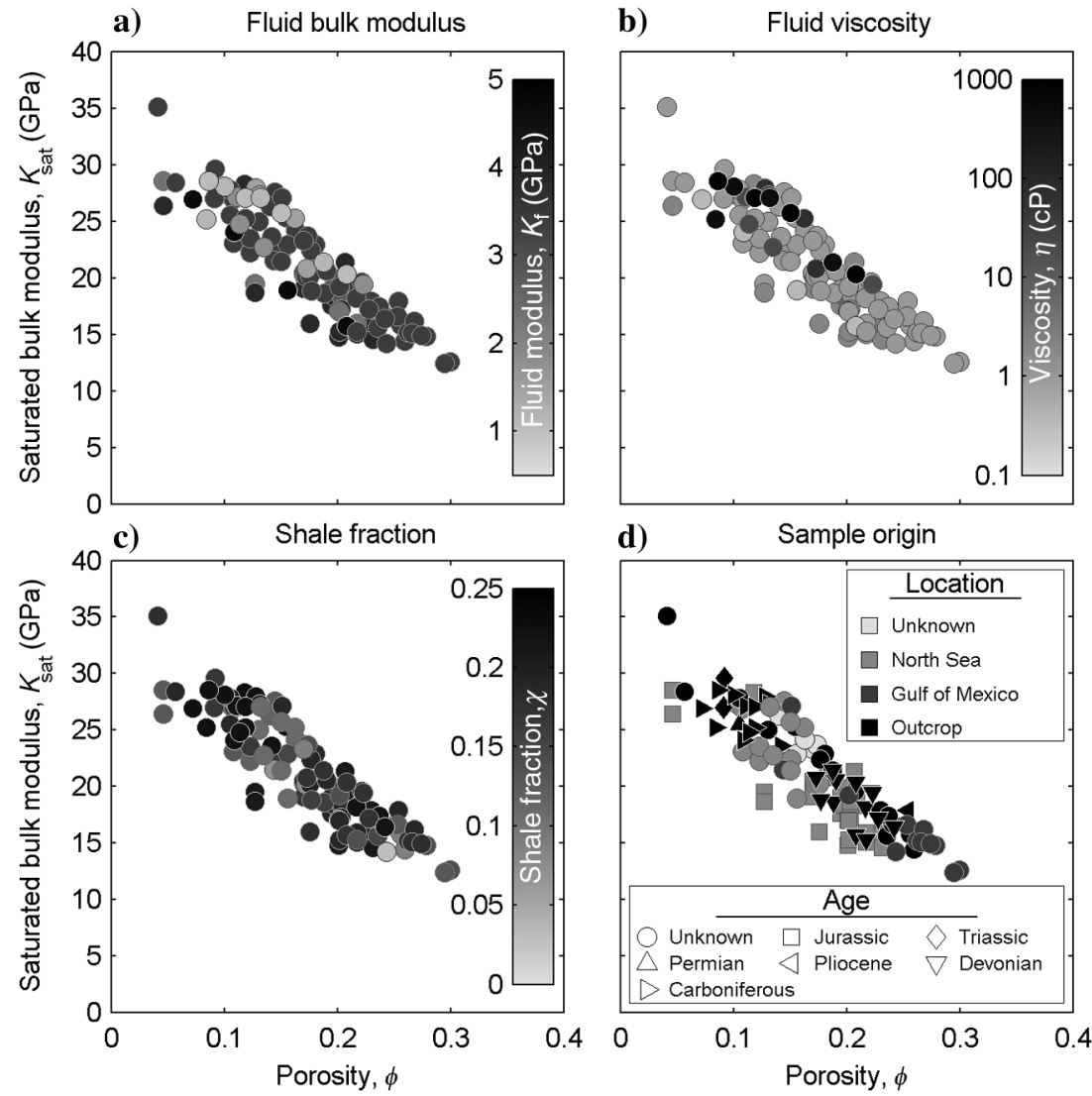

Figure 11. Overview of the sandstone data. The saturated bulk modulus is plotted versus porosity and shaded to (a) fluid bulk modulus, (b) fluid viscosity, (c) shale fraction, and (d) geologic location and age. modulus. This implies that the shale frame bulk modulus is also higher than the fluid bulk modulus, and that the pore-filling modulus for dispersed shale can be determined from equation 11 for samples in the high-frequency state and from equation 12 for samples in the low-frequency state. In both cases, the pore-filling modulus is determined by the Reuss average. If we observe the limiting case in which the shale bulk modulus is much higher than the fluid modulus, we get

$$
\frac{S_{\mathrm{sh}}}{K_{\mathrm{sh}}^{\mathrm{sat}}} \rightarrow 0
$$

The high-frequency case is used as an example. The equivalent limit applies to the low-frequency case with the ratio replaced by $S_{c} / K_{0}^{c}$. The limit involves a shale fraction that is less than unity: $S_{\mathrm{sh}}<1$, whereby the shale modulus need not be much higher than the fluid modulus to dominate the suspension modulus (Figure 12). The maximum pore-filling modulus is consequently

$$
K_{\mathrm{unr}}^{\max }=\frac{K_{f}}{1-S_{\mathrm{sh}}} .
$$

An equivalent analysis applied to equation 12 gives a maximal porefilling modulus of $K_{0}^{c} /\left(1-S_{c}\right)$. The fluid modulus constitutes the lower bound for the pore-filling modulus. When the pore-filling modulus is equal to the fluid modulus, Gassmann's equations are accurate.

The apparent pore-filling moduli from equation 14 must conform to these bounds for the fluid effect to be explained by clay squirt from dispersed shale:

$$
K_{f}<K_{\mathrm{pfa}}^{\mathrm{gass}}<\frac{K_{f}}{1-S_{\mathrm{sh}}} .
$$

The data are accordingly plotted versus the upper bound in Figure 13, although the maximum porefilling modulus is only truly achieved at $K_{\text {sh }} \rightarrow \infty$. This has the implication that if the apparent pore-filling modulus exceeds the maximum pore-filling modulus, the dispersion cannot be caused by shale in the pore space and cannot be described by clay squirt from dispersed shale.

A higher apparent pore-filling modulus than the upper bound could be associated with a contribution to clay squirt from load-bearing shale, and, accordingly, Figure 14 shows the data points with $K_{\mathrm{pfa}}^{\mathrm{gas}}>K_{\mathrm{unr}}^{\max }$ compared with the prediction for laminated shale from Figure 8. In a laminated texture, the clay-squirt effect depends directly on the clay mineral moduli, and Figure 14 illustrates that the excess fluid effect can be described within the clay-squirt model assuming a loadbearing shale with the clay mineral moduli agreeing with the data reported in the literature.

Some samples have apparent pore-filling moduli lower than the fluid modulus (Figure 13). This cannot be explained by clay squirt because $K_{F}$ is the lower bound for the pore-filling 
modulus. Samples that have apparent pore-filling moduli lower than the fluid modulus are generally samples with high permeability $(k>200 \mathrm{mD})$ and with a significant shale fraction. The permeability may then be governed by the intergrain porosity (Rosenbrand and Fabricius, 2015), and fluid may bypass the microporosity causing the shale part to have lower saturation than assumed from the saturation procedure. The shale modulus could therefore be closer to the dry shale modulus, which drastically reduces the pore-filling modulus.

If we focus on the data that, according to Figure 13, are compatible with the clay-squirt model, and we assume that the difference between the apparent pore-filling and the fluid moduli is caused by shale in the pore space, we conclude that the shale must be either in the high-frequency state with a pressure gradient between the shale microporosity and the effective porosity, or it may be in the low-frequency state with a uniform pore pressure. Using the apparent pore-filling moduli from equation 14, we can calculate the apparent shale bulk modulus from equation 11 and the apparent clay mineral bulk modulus from equation 12 . We also have to account the different saturation fractions of shale and clay as the former contains both solid clay material and microporosity. The saturation fractions are:

$$
S_{\mathrm{sh}}=\frac{\chi}{\phi_{\mathrm{frame}}} \neq S_{c}=\frac{\chi\left(1-\phi_{\mathrm{sh}}\right)}{\phi_{\mathrm{frame}}} .
$$

We assume that the porosity of the quartz frame is the porosity at which the given dry modulus conforms to the MUHS bound as proposed by Gal et al. (1999), so to quantify the clay fraction, we fit the dry moduli to the MUHS using a bisection algorithm, and we assume that the difference between the measured and the frame porosities is the clay occupying some of the pore space:

$$
x_{c}=\frac{V_{\text {clay }}}{V}=\phi_{\text {frame }}-\phi .
$$

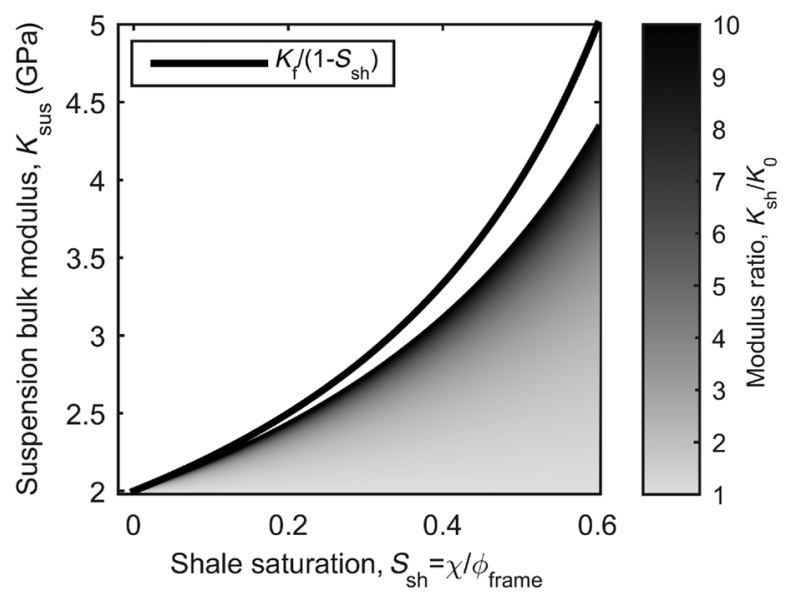

Figure 12. Limiting behavior of the suspension modulus versus shale saturation. The suspension modulus at low shale saturation quickly approaches the upper limit. The same relation is valid for the clay mineral saturation replacing the shale parameters with the clay mineral parameters.
The shale fraction from image analysis is the clay fraction plus the microporosity; therefore, the shale porosity is

$$
\phi_{\mathrm{sh}}=1-\frac{\phi_{\mathrm{frame}}-\phi}{\chi} .
$$

With this, we can solve equation 11 for $K_{\text {sh }}$ and equation 12 for $K_{0}^{c}$. If we restrict $K_{\mathrm{sh}}$ and $K_{0}^{c}$ to be less than $50 \mathrm{GPa}$, no sample can fulfil both equations 11 and 12 . We interpret this to mean that the samples are found either in the high-frequency regime or in the low-frequency regime depending on by which equation a solution can be found. Accordingly, in Figure 15a, the data that provide moduli for the high-frequency regime are plotted versus shale porosity, and in Figure 15b, the data that provide moduli for the low-frequency regime are plotted versus shale porosity.

The data consistent with a high-frequency regime show decreasing trends in the shale frame modulus with increasing shale porosity, which is to be expected for a frame modulus (Figure 15a). Two trends are identifiable: one that points to a clay mineral modulus (extrapolation to $\phi_{\mathrm{sh}}=0$ ) of approximately $25 \mathrm{GPa}$ and one pointing to a clay mineral bulk modulus of $40 \mathrm{GPa}$. The latter trend contains few definite data points, whereas the former is better resolved. Shales in sandstone are mixtures of different minerals, and this complicates the interpretation, but the lower trend in Figure 15a is consistent with a kaolinite mineralogy (Table 1). The data in Figure 15a and $15 \mathrm{~b}$ are color coded to the location of the samples. Figure 15a shows good consistency with North Sea samples having dominantly kaolinite mineralogy.

The samples consistent with the low-frequency regime in Figure $15 \mathrm{~b}$ show clay mineral moduli independent of shale porosity

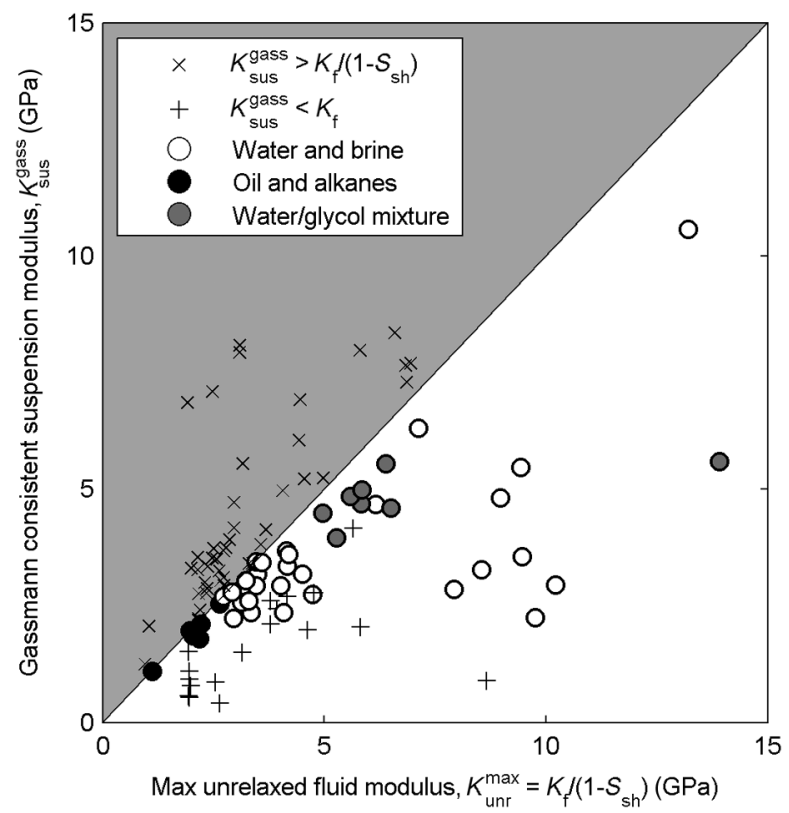

Figure 13. Apparent pore-filling modulus for the data compared with the maximum pore-filling modulus (from equation 16). Data with circular labels are consistent with clay-squirt dispersion, data in the gray field labeled by x's have a too-high fluid effect on the bulk modulus, and data labeled by +'s have a too-low fluid effect on the bulk modulus. 
as expected for a mineral modulus. The mineral moduli cluster around three values of seven (4 data), 22 (2 data), and $37 \mathrm{GPa}$ (2 data), respectively. The two larger mineral moduli correspond well with the extrapolated mineral moduli in Figure 15a. They are also plausible when compared with the data in Table 1. We have no direct measure of the relaxation state of the samples, and so it is not certain that the moduli depicted in Figure 15 belong to either the high-frequency or the low-frequency regime. The actual relaxation state may, in principle, be between the relaxed and unrelaxed states, but the correlation between shale moduli and shale porosity in Figure 15a and the absence of this correlation in Figure 15b, support the interpretation of the relaxation states because a bulk modulus only depends on porosity if the porosity is compressed in the compression considered. That is, to observe a porosity-dependent shale modulus, there has to be a pressure difference between the fluid outside the shale and inside the shale. Without a pressure difference between the inside and outside, the modulus of the shale is determined by the mineral modulus and therefore independent of porosity, which is exactly what we observe in Figure $15 \mathrm{~b}$.
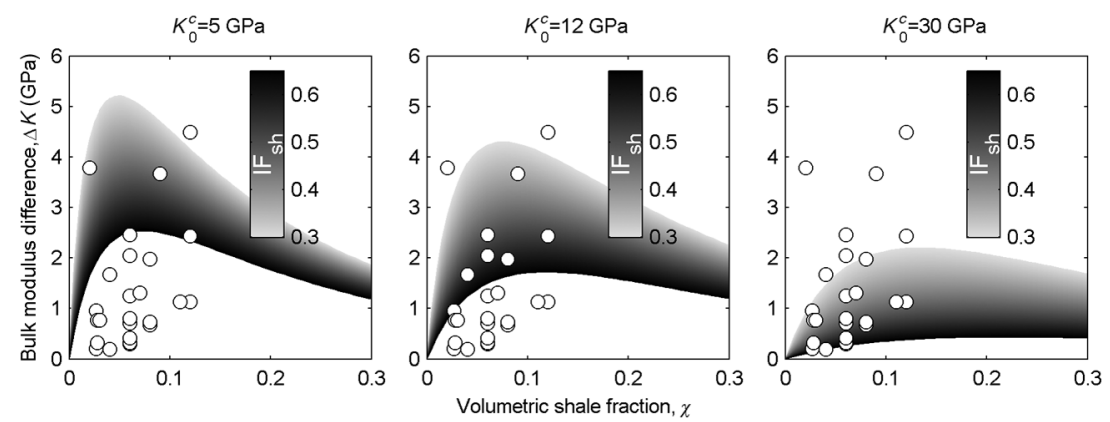

Figure 14. Data from Figure 13 with $K_{\mathrm{pfa}}^{\mathrm{gass}}>K_{\mathrm{sus}}^{\max }$ compared qualitatively with the predictions from the laminated model at three different clay mineral moduli. The dispersion for these data can be accounted for by load-bearing shale.
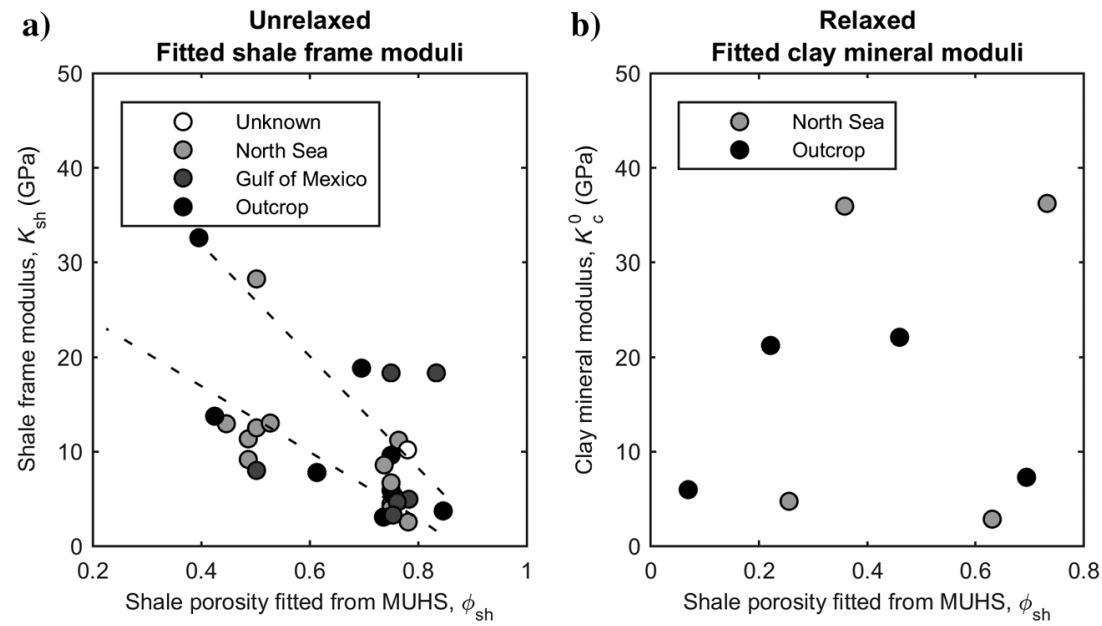

Figure 15. (a) Fitted saturated shale moduli from lithologies with unrelaxed dispersed shale versus shale porosity. Two trends are seen correlating the saturated shale moduli with the shale porosity: one trend with a grain modulus at zero porosity of approximately $40 \mathrm{GPa}$ and one with approximately $25 \mathrm{GPa}$. (b) Fitted clay mineral moduli for relaxed samples plotted versus shale porosity show no correlation. Three distinct mineral moduli are, however, identified in which the two are compatible with the grain moduli in (a).

\section{CONCLUSION}

We have presented a simple model capable of quantifying the possible dispersion of bulk modulus in sandstone arising from ed pressure gradients in the microporosity of clay mineral asclay squirt can cause significant dispersion on the bulk modulus in sandstones. lus. The relation between clay-squirt dispersion and shale fraction also differs between the two textures. For sandstone with clay laminae, clay-squirt dispersion on the bulk modulus reaches a maximum at an intermediate shale fraction of approximately 0.2 , whereas for dispersed shale, clay-squirt dispersion increases monotonically with the shale fraction.

Literature data for sandstones with predominantly dispersed shale were evaluated by comparison with the model. The model predicts dispersion from clay squirt arising from dispersed shale smaller than the dispersion observed in much of the data. These discrepancies could be caused by clay squirt from load-bearing shale in the framework.

The samples with dispersion agreeing with clay-squirt dispersion for dispersed shale can be separated into a group in the low-frequency state of clay squirt and a group in the high-frequency state. In both groups, the observed suspension modulus was determined. From the suspension modulus, the modulus of the solid in the pore space was determined. For the high-frequency samples, the solid modulus correlates with the shale porosity. This suggests that the solid modulus is the shale frame bulk modulus and not the bulk modulus of the clay minerals. This supports the notion of a pressure difference between the microporosity of the dispersed shale and the effective porosity, leading to clay-squirt dispersion. For the samples in the low-frequency state, no correlation was observed between the solid modulus and the shale porosity, indicating the solid modulus is the clay mineral bulk modulus. This supports the assumption that the pressure is equilibrated in the pores for these samples. The observation of these two distinct states directly shows the clay-squirt mechanism to be present.

The simple model developed in this study shows that dispersion in shaly sandstones can be associated with clay-squirt dispersion. The possible magnitude of the clay-squirt dispersion is large enough to account for the dispersion in many cases. 


\section{ACKNOWLEDGMENTS}

The authors acknowledge constructive comments to earlier versions of this paper from five anonymous reviewers and an associate editor. DONG Energy is thanked for economic sponsorship of M. K. Sørensen.

\section{APPENDIX A}

\section{THE ISOFRAME MODEL}

The full solid cross section of a porous medium is given by $(1-\phi)$. The isoframe model divides the solid cross section into a load-bearing fraction and a suspended fraction. The load-bearing fraction is denoted by the isoframe value $x_{\mathrm{IF}}$. Hereby, the load-bearing solid cross section is $x_{\mathrm{IF}}(1-\phi)$, and the suspended fraction of the solid cross section is $\left(1-x_{\mathrm{IF}}\right)(1-\phi)$. The total cross sectional area not participating in the load-bearing framework is the suspended solid fraction and the porosity.

The moduli of the load-bearing framework are determined by assuming that the load-bearing framework conforms to the upper Hashin-Shtrikman bound. The solid is characterized by the mineral moduli $\left(K_{0}, G_{0}\right)$. The fluid is mixed with the non-load-bearing solid to form a suspension. The total non-load-bearing cross section is $1-x_{\mathrm{IF}}(1-\phi)$. Of this, fluid composes the fraction given by $\phi$ and the rest is suspended solid. Under the assumption of pressure equilibrium on the pore scale, the suspension $K_{\text {sus }}$ can be determined by the Reuss average of the fluid modulus $K_{f}$, and the mineral modulus $K_{0}$ weighted by the fraction of fluid and solid. The weights are given by the cross sectional fraction involved in the load-bearing frame $S_{f}$, and the cross sectional fraction not involved in the load-bearing frame $S_{s}$ :

$$
\begin{gathered}
S_{f}=\frac{\phi}{1-x_{\mathrm{IF}}(1-\phi)}, \\
S_{s}=\frac{\left(1-x_{\mathrm{IF}}\right)(1-\phi)}{1-x_{\mathrm{IF}}(1-\phi)} .
\end{gathered}
$$

The suspension modulus $K_{\text {sus }}$ becomes

$$
K_{\mathrm{sus}}=\left(\frac{S_{f}}{K_{f}}+\frac{S_{s}}{K_{0}}\right)^{-1}
$$

This suspension modulus is for the pore fill of the load-bearing framework. The values are inserted into the upper Hashin-Shtrikman bound to determine the framework moduli expressed from $x_{\mathrm{IF}}$ and porosity (Fabricius et al., 2010):

$$
\begin{gathered}
K=\left(\frac{1-x_{\mathrm{IF}}(1-\phi)}{K_{\mathrm{sus}}+\frac{4}{3} G_{0}}+\frac{x_{\mathrm{IF}}(1-\phi)}{K_{0}+\frac{4}{3} G_{0}}\right)^{-1}-\frac{4}{3} G_{0}, \\
G=\left(\frac{1-x_{\mathrm{IF}}(1-\phi)}{\xi}+\frac{X_{\mathrm{IF}}(1-\phi)}{G_{0}+\xi}\right)^{-1}-\xi,
\end{gathered}
$$

where

$$
\xi=\frac{G_{0}}{6}\left(\frac{9 K_{0}+8 G_{0}}{K_{0}+2 G_{0}}\right) .
$$

The formulation of the Hashin-Shtrikman bounds follows Berryman (1995).

\section{APPENDIX B \\ DERIVATION OF THE SHALE LAMINAE EQUATION}

This appendix provides the detailed derivation of equation 9 . The requirement of mass conservation is

$$
\frac{d m_{q}^{\mathrm{HF}}}{d \sigma}-\frac{d m_{q}^{\mathrm{LF}}}{d \sigma}=-\left(\frac{d m_{\mathrm{sh}}^{\mathrm{HF}}}{d \sigma}-\frac{d m_{\mathrm{sh}}^{\mathrm{LF}}}{d \sigma}\right),
$$

where $d m_{q}^{\mathrm{HF}}$ is the change in fluid mass in the quartz frame at high frequency, $d m_{q}^{\mathrm{LF}}$ is the change in fluid mass in the quartz frame at low frequency, and $d m_{\mathrm{sh}}^{\mathrm{HF}}$ and $d m_{\mathrm{sh}}^{\mathrm{LF}}$ are the corresponding changes in fluid mass for the shale frame. The changes in fluid mass can be split into changes in pore volume and changes in fluid density (i.e., compression):

$$
\frac{d m}{d \sigma}=\rho \frac{d V_{p}}{d \sigma}+V_{p} \frac{d \rho}{d \sigma} .
$$

Zimmerman et al. (1986) express the pore compressibility with pore pressure at constant confining pressure $C_{\mathrm{pp}}$ :

$$
C_{\mathrm{pp}}=\left.\frac{1}{V_{p}} \frac{\partial V_{p}}{\partial P}\right|_{\sigma},
$$

where $V_{p}$ is the pore volume and $P$ is the pore pressure. Substituting this into equation B-2 yields an expression for the fluid mass $m$ change with confining stress

$$
\begin{aligned}
\frac{1}{\rho} \frac{d m}{d \sigma} & =V_{p} C_{\mathrm{pp}} \frac{d P}{d \sigma}+V_{p} \frac{1}{K_{f}} \frac{d P}{d \sigma}, \\
& =V_{p}\left(C_{\mathrm{pp}}+\frac{1}{K_{f}}\right) \frac{d P}{d \sigma}, \\
& =V_{p . i} B_{i} \frac{d P_{i}^{j}}{d \sigma},
\end{aligned}
$$

where $B_{i}$ is the induced pressure relative to the applied external stress for frame $i$, equivalent to Skempton's B coefficient. Here, $P_{i}^{j}$ is the pore pressure in frame $i$ in the state $j$. The state can be low frequency LF or high frequency HF. This expression is substituted into each side of equation 5 to produce 


$$
\begin{aligned}
\frac{d m_{i}^{\mathrm{HF}}}{d \sigma}-\frac{d m_{i}^{\mathrm{LF}}}{d \sigma} & =V_{p, i} B_{i} \frac{d P_{i}^{\mathrm{HF}}}{d \sigma}-V_{p, i} B_{i} \frac{d P^{\mathrm{LF}}}{d \sigma}, \\
& =V_{p, i}\left[B_{i} \frac{d P_{i}^{\mathrm{HF}}}{d \sigma}-B_{i} \frac{d P^{\mathrm{LF}}}{d \sigma}\right] \\
& =V_{p, i}\left(\frac{d P_{q}^{\mathrm{HF}}}{d \sigma}-\frac{d P^{\mathrm{LF}}}{d \sigma}\right) B_{i}
\end{aligned}
$$

for the framework component $i$, where $i$ refers either to the quartz framework or to the shale framework. With this, equation 5 becomes

$$
\begin{gathered}
V_{p, q}\left(\frac{d P_{q}^{\mathrm{HF}}}{d \sigma}-\frac{d P^{\mathrm{LF}}}{d \sigma}\right) B_{q}=-V_{p, \mathrm{sh}}\left(\frac{d P_{\mathrm{sh}}^{\mathrm{HF}}}{d \sigma}-\frac{d P^{\mathrm{LF}}}{d \sigma}\right) B_{\mathrm{sh}}, \\
f_{q}\left(\frac{d P_{q}^{\mathrm{HF}}}{d \sigma}-\frac{d P^{\mathrm{LF}}}{d \sigma}\right) B_{q}=-f_{\mathrm{sh}}\left(\frac{d P_{\mathrm{sh}}^{\mathrm{HF}}}{d \sigma}-\frac{d P^{\mathrm{LF}}}{d \sigma}\right) B_{\mathrm{sh}}, \\
\frac{d P^{\mathrm{LF}}}{d \sigma}\left[f_{\mathrm{sh}} B_{\mathrm{sh}}+f_{q} B_{q}\right]=f_{q} B_{q} \frac{d P_{q}^{\mathrm{HF}}}{d \sigma}+f_{\mathrm{sh}} B_{\mathrm{sh}} \frac{d P_{\mathrm{sh}}^{\mathrm{HF}}}{d \sigma}, \\
\frac{d P^{\mathrm{LF}}}{d \sigma}\left[f_{\mathrm{sh}} C_{\mathrm{pp}, \mathrm{sh}}+f_{q} C_{\mathrm{pp}, q}+\frac{1}{K_{f}}\right] \\
=f_{q} B_{q} \frac{d P_{q}^{\mathrm{HF}}}{d \sigma}+f_{\mathrm{sh}} B_{\mathrm{sh}} \frac{d P_{\mathrm{sh}}^{\mathrm{HF}}}{d \sigma} .
\end{gathered}
$$

In the last step, it was used that

$$
f_{q}+f_{s h}=1
$$

whereby

$$
\frac{1}{K_{f}}=f_{q} \frac{1}{K_{f}}+f_{\text {sh }} \frac{1}{K_{f}} .
$$

Isolating $d P^{\mathrm{LF}} / d \sigma$ in equation B-6 leads to equation 9.

\section{REFERENCES}

Anstey, N. A., 1991, Velocity in thin section: First Break, 9, 449-457. Berryman, J. G., 1995, Mixture theory for rock properties, in T. J. Ahrens, ed., Rock physics and phase relations: A handbook of physical constants: John Wiley \& Sons, 205-228.

Best, A. I., 1992, The prediction of the reservoir properties of sedimentary rocks from seismic measurements: Ph.D. thesis, University of Reading.

Best, A. I., T. Han, and J. Sothcott, 2013, Elastic wave attenuation and electrical formation factor of shaly sandstones: Presented at the 2nd International Workshop on Rock Physics, EAGE.

Best, A. I., and C. McCann, 1995, Seismic attenuation and pore-fluid viscosity in clay-rich reservoir sandstones: Geophysics, 60, 1386-1397, doi: $10.1190 / 1.1443874$

Best, A. I., C. McCann, and J. Sothcott, 1994, The relationships between the velocities, attenuations and petrophysical properties of reservoir sedimentary rocks: Geophysical Prospecting, 42, 151-178, doi: 10.1111/j 1365-2478.1994.tb00204.x.

Biot, M. A., 1962, Mechanics of deformation and acoustic propagation in porous media: Journal of Applied Physics, 33, 1482-1498, doi: 10.1063/1 .1728759 .

Ciz, R., and S. A. Shapiro, 2007, Generalization of Gassmann equations for porous media saturated with a solid material: Geophysics, 72, no. 6, A75A79, doi: 10.1190/1.2772400.

David, E. C., and R. W. Zimmerman, 2012, Pore structure model for elastic wave velocities in fluid-saturated sandstones: Journal of Geophysical Research: Solid Earth, 117, B07210, doi: 10.1029/2012JB009195.

Dvorkin, J., G. Mavko, and A. Nur, 1995, Squirt flow in fully saturated rocks: Geophysics, 60, 97-107, doi: 10.1190/1.1443767.
Fabricius, I. L., G. T. Bächle, and G. P. Eberli, 2010, Elastic moduli of dry and water saturated carbonates: Effect of depositional texture, porosity, and permeability: Geophysics, 75, no. 3, N65-N78, doi: 10.1190/1 .3374690 .

Gal, D., J. Dvorkin, and A. Nur, 1998, A physical model for porosity reduction in sandstones: Geophysics, 63, 454-459, doi: 10.1190/1.1444346.

Gal, D., J. Dvorkin, and A. Nur, 1999, Elastic-wave velocities in sandstones with non-load-bearing clay: Geophysical Research Letters, 26, 939-942, doi: 10.1029/1999GL900106.

Gurevich, B., D. Makarynska, O. B. de Paula, and M. Pervukhina, 2010, A simple model for squirt-flow dispersion and attenuation in fluid-saturated granular rocks: Geophysics, 75, no. 6, N109-N120, doi: 10.1190/1 .3509782 .

Han, D.-H., 1986, Effects of porosity and clay content on acoustic properties of sandstones and unconsolidated sediments: Ph.D. thesis, Stanford University.

Hansen, S., 1996, A compaction trend for Cretaceous and Tertiary shales on the Norwegian shelf based on sonic transit times: Petroleum Geoscience, 2, 159-166, doi: 10.1144/petgeo.2.2.159.

Hudson, J., 1981, Wave speeds and attenuation of elastic waves in material containing cracks: Geophysical Journal International, 64, 133-150, doi: 10.1111/j.1365-246X.1981.tb02662.x.

Hurst, A., and P. Nadeau, 1995, Clay microporosity in reservoir sandstones: An application of quantitative electron microscopy in petrophysical evaluation: AAPG Bulletin, 79, 563-573.

Jizba, D. L., 1991, Mechanical and acoustical properties of sandstones and shales: Ph.D. thesis, Stanford University.

King, M. S., 1966, Wave velocities in rocks as a function of changes in overburden pressure and pore-fluid saturants: Geophysics, 31, 50-73, doi: 10 $.1190 / 1.1439763$.

King, M. S., and J. R. Marsden, 2002, Velocity dispersion between ultrasonic and seismic frequencies in brine-saturated reservoir sandstones: Geophysics, 67, 254-258, doi: 10.1190/1.1451700.

King, M. S., J. R. Marsden, and J. W. Dennis, 2000, Biot dispersion for P- and S-wave velocities in partially and fully saturated sandstones: Geophysical Prospecting, 48, 1075-1089, doi: 10.1046/j.1365-2478.2000 .00221.x.

Klimentos, T., 1991, The effects of porosity-permeability-clay content on the velocity of compressional waves: Geophysics, 56, 1930-1939, doi: 10 $.1190 / 1.1443004$.

Koga, I., M. Aruga, and Y. Yoshinaka, 1958, Theory of plane elastic waves in a piezoelectric crystalline medium and determination of elastic and piezoelectric constants of quartz: Physical Review, 109, 1467-1473, doi: 10 .1103/PhysRev.109.1467.

Leurer, K. C., 1997, Attenuation in fine-grained marine sediments: Extension of the Biot-Stoll model by the effective grain model (EGM): Geophysics, 62, 1465-1479, doi: 10.1190/1.1444250.

Makarynska, D., B. Gurevich, J. Behura, and M. L. Batzle, 2010, Fluid substitution in rocks saturated with viscoelastic fluids: Geophysics, $\mathbf{7 5}$, no. 2 , E115-E122, doi: 10.1190/1.3360313.

Marion, D., and A. Nur, 1991, Pore-filling material and its effect on velocity in rocks: Geophysics, 56, 225-230, doi: 10.1190/1.1443034.

Marketos, G., and A. I. Best, 2010, Application of the BISQ model to clay squirt flow in reservoir sandstones: Journal of Geophysical Research, 115, B06209, doi: 10.1029/2009JB006495.

Mavko, G., and D. L. Jizba, 1991, Estimating grain-scale fluid effects on velocity dispersion in rocks: Geophysics, 56, 1940-1949, doi: 10.1190/1 .1443005 .

Mavko, G., and T. Mukerji, 1995, Seismic pore space compressibility and Gassmann's relation: Geophysics, 60, 1743-1749, doi: 10.1190/1.1443907.

Mayr, S. I., and H. Burkhardt, 2006, Ultrasonic properties of sedimentary rocks: Effect of pressure, saturation, frequency and microcracks: Geophysical Journal International, 164, 246-258, doi: 10.1111/j.1365-246X.2005 $.02826 . x$.

Minshull, T., and R. White, 1989, Sediment compaction and fluid migration in the Makran accretionary prism: Journal of Geophysical Research, 94, 7387-7402, doi: 10.1029/JB094iB06p07387.

Mondol, N. H., K. Bjørlykke, J. Jahren, and K. Høeg, 2007, Experimental mechanical compaction of clay mineral aggregates: Changes in physical properties of mudstones during burial: Marine and Petroleum Geology, 24, 289-311, doi: 10.1016/j.marpetgeo.2007.03.006.

Mondol, N. H., J. Jahren, K. Bjørlykke, and I. Brevik, 2008, Elastic properties of clay minerals: The Leading Edge, 27, 758-770, doi: 10.1190/1 .2944161

Paula, O. D., and M. Pervukhina, 2012, Modeling squirt dispersion and attenuation in fluid-saturated rocks using pressure dependency of dry ultrasonic velocities: Geophysics, 77, no. 3, WA157-WA168, doi: 10.1190/ geo2011-0253.1.

Pervukhina, M., D. N. Dewhurst, B. Gurevich, U. Kuila, A. F. Siggins, M. D. Raven, and H. M. N. Bolås, 2008, Stress-dependent elastic properties of shales: Measurement and modeling: The Leading Edge, 27, 772-779, doi: 10.1190/1.2944162. 
Pimienta, L., J. Fortin, and Y. Guéguen, 2015, Bulk modulus dispersion and attenuation in sandstones: Geophysics, 80, no. 5, D111-D127, doi: 10 .1190/geo2014-0335.1.

Rice, J., and M. Cleary, 1976, Some basic stress diffusion solutions for fluidsaturated elastic porous media with compressible constituents: Reviews of Geophysics, 14, 227-241, doi: 10.1029/RG014i002p00227.

Rosenbrand, E., and I. L. Fabricius, 2015, Permeability in Rotliegend gas sandstones to gas and brine as predicted from NMR, mercury injection and image analysis: Marine and Petroleum Geology, 64, 189-202, doi: 10.1016/j.marpetgeo.2015.02.009.

Saxena, N., and G. Mavko, 2014, Exact equations for fluid and solid substitution. Geophysics, 79, no. 3, L21-L32, doi: 10.1190/geo2013-0187.1.

Shapiro, S. A., 2003, Elastic piezosensitivity of porous and fractured rocks: Geophysics, 68, 482-486, doi: 10.1190/1.1567215.

Skempton, A., 1954, The pore-pressure coefficients A and B: Geotechnique, 4, 143-147, doi: 10.1680/geot.1954.4.4.143.

Tosaya, C., 1982, Acoustical properties of clay-bearing rocks: Ph.D. thesis, Stanford University.
Vanorio, T., M. Prasad, and A. Nur, 2003, Elastic properties of dry clay mineral aggregates, suspensions and sandstones: Geophysical Journal International, 155, 319-326, doi: 10.1046/j.1365-246X.2003 .02046.x.

Wang, Z., H. F. Wang, and M. Cates, 2001, Effective elastic properties of solid clays: Geophysics, 66, 428-440, doi: 10.1190/1.1444934.

Wilson, M., and E. Pittman, 1977, Authigenic clays in sandstones: Recognition and influence on reservoir properties and paleoenvironmental analysis: Journal of Sedimentary Petrology, 47, 3-31.

Yin, H., 1992, Acoustic velocity and attenuation of rocks: Isotropy, intrinsic anisotropy, and stress induced anisotropy: Ph.D. thesis, Stanford University.

Zimmerman, R. W., 2000, Coupling in poroelasticity and thermoelasticity: International Journal of Rock Mechanics and Mining Sciences, 37, 79-87, doi: 10.1016/S1365-1609(99)00094-5.

Zimmerman, R. W., W. H. Somerton, and M. S. King, 1986, Compressibility of porous rocks: Journal of Geophysical Research, 91, 12765-12777, doi: 10.1029/JB091iB12p12765. 